\title{
KESANTUNAN BERBAHASA SISWA DI SMA MUHAMMADIYAH 4 SURABAYA
}

\author{
Bima Saksono Putra \\ SMA Kusumanagara \\ Putrasely66@gmail.com
}

\begin{abstract}
ABSTRAK
Kesantunan Berbahasa siswa di SMA Muhammadiyah 4 Surabaya terlihat ketika siswa bertutur sesuai dengan maksim kesantunan yang berlaku. Penelitian ini bertujuan untuk mendeskripsikan kesantunan berbahasa siswa di SMA Muhammadiyah 4 Surabaya. Metode yang digunakan dalam penelitian ini adalah metode kualitatif deskriptif dengan data tuturan antara siswa dengan guru di SMA Muhammadiyah 4 Surabaya. Teknik pengumpulan data dengan cara simak bebas lihat catat dan rekam suara. Teknik analisis data dengan menyusun data secara sistematis data yang diperoleh dari pengamatan dan catatan lapangan. Hasil penelitian ini dapat disimpulkan bahwa wujud kesantunan berbahasa siswa di SMA Muhammadiyah 4 Surabaya terlihat ketika siswa bertutur sesuai dengan maksim kearifan, maksim kedermawanan, maksim pujian, maksim kerendahan hati, maksim kesepakatan dan maksim kesimpatian.
\end{abstract}

Kata kunci: Kesantunan siswa ,wujud kesantunan,wujud penyimpangan prinsip kesantunan.

\begin{abstract}
Student speaking politeness in Muhammadiyah 4 Surabaya High School is seen when students speak in accordance with the applicable politeness maxim. This study aims to describe the politeness of the language of students in Muhammadiyah 4 High School Surabaya. The method used in this research is descriptive qualitative method with data utterance between students and teachers at Muhammadiyah 4 Surabaya High School. Data collection techniques by referring freely see note and record sound. Data analysis techniques by compiling systematic data data obtained from observations and field notes. The results of this study can be concluded that the form of students' language politeness in Muhammadiyah 4 Surabaya High School. seen when students speak according to the wisdom maxim, the maxim of generosity, the maxim of praise, the maxim of humility, the maxim of agreement and the maxim of conscience.
\end{abstract}

Keywords: Student, a form of politeness, a form of irregularity in the principle of politeness. 


\section{PENDAHULUAN}

Kesantunan berbahasa merupakan hal yang harus diperhatikan seseorang dalam berkomunikasi sebab ketika proses komunikasi berlangsung dapat terjadi gesekangesekan yang mengakibatkan terjadinya konflik psikologis maupun fisik antara penutur dan mitra tutur. Maka dari itu, setiap orang perlu memerhatikan prinsip kesantunan berbahasa dalam bertutur sebagai bentuk perilaku yang baik dan harmonis antara penutur dan lawan tutur. Hal ini sejalan dengan pendapat Leech dalam Oka (2015: 124) yang menyatakan bahwa dengan prinsip kesantunan dapat menjaga keseimbangan sosial dan keramahan hubungan dalam sebuah percakapan. Penggunaan prinsip kesantunan berbahasa dalam sebuah tuturan juga dimaksudkan agar masing-masing pihak dapat mengendalikan diri dan tidak emosional sehingga pada akhirnya tidak ada pihak yang saling dirugikan baik itu dari segi penutur maupun mitra tutur. Selain itu, prinsip kesantunan berbahasa bertujuan untuk mengurangi ketidaksopanan dalam sebuah tuturan dan bagaimana agar dapat memproduksi sebuah tuturan tanpa menyinggung perasaan orang lain.

Kesantunan berbahasa memiliki kriteria-kriteria kesantunan yang harus ditaati oleh peserta pertuturan. Pertuturan tersebut membimbing para peserta pertuturan untuk menciptakan pertuturan yang efektif, yang terhindar dari kesalahpahaman dan juga tidak menyinggung perasaan orang lain. Banyak para ahli yang menjelaskan kriteria-kriteria dalam menulis teori kesantunan berbahasa Brown dan Levinson, dan Geoffrey Leech merupakan pakar yang merumuskan kriteria-kriteria kesantuna ke dalam teori kesantunan berbahasa.

Prinsip kesantunan berbahasa seharusnya sudah diterapkan dalam interaksi belajar mengajar bahasa Indonesia. Pada umumnya, karateristik siswa perkotaan khususnya di SMA Muhammadiyah 4 Surabaya saat ini lebih menyukai menggunakan Bahasa yang ceplas-ceplos atau asal berbicara dan tidak berpikir atau memperhatikan situasi siswa sedang berada dilingkungan sekolah. Gaya bahasa dengan keseharian dengan model tersebut dianggap sebagai cara sederhana dan cepat untuk menyapaikan sesuatu, sering kali tidak disadari sehingga mereka juga menerapkan ketika berbicara dengan guru. Peristiwa tersebut terjadi baik di dalam kelas maupun di luar kelas. 


\section{METODE PENELITIAN}

Penelitian Kesantunan Berbahasa pada Percakapan Siswa dengan Guru di SMA Muhammadiyah 4 Surabaya ini termasuk ke dalam penelitian deskriptif kualitatif. Menurut Moleong (2007: 6), penelitian kualitatif merupakan penelitian yang bermaksud untuk memahami fenomena tentang apa yang dialami oleh subjek penelitian misalnya perilaku, persepsi, motivasi, dan tindakan. Sementara itu, Djajasudarma (1993: 10) menyebutkan bahwa penelitian kualitatif merupakan penelitian yang menghasilkan data deskriptif berupa data tertulis atau lisan di masyarakat bahasa.

Penelitian ini menggunakan metode penelitian deskriptif kualitatif. Djam’an Satori (2011: 23) mengungkapkan bahwa penelitian kualitatif dilakukan karena peneliti ingin mengeksplor fenomena-fenomena yang tidak dapat dikuantifikasikan yang bersifat deskriptif seperti proses suatu langkah kerja, formula suatu resep, pengertian-pengertian tentang suatu konsep yang beragam, karakteristik suatu barang dan jasa, gambar-gambar, gaya-gaya, tata cara suatu budaya, model fisik suatu artifak dan lain sebagainya. Teknik analisis data dalam menganalisis data, peneliti melakukan tahapan-tahapan sebagai berikut.

1. Merekam dan mencatat langsung tuturan guru yang diduga mengandung prinsip kesantunan berbahasa beserta maksim-maksimnya ketika memberikan penguatan.

2. Menelaah data yang telah terkumpul melalui obeservasi, pencatatan lapangan dengan melakukan transkripsi data kedalam tulisan.

3. Semua data yang telah terkumpul dikategorikan dan dikelompokkan sesuai dengan fokus penelitian yang diinginkan.

4. Data diseleksi mana yang relavan dan tidak relavan dengan yang diharapkan. Data yang relavan dianalisis sementara data yang tidak relavan dibuang berdasarkan maksim-maksim penggolongan prinsip kesantunan berbahasa.

5. Selanjutnya, data dianalisis sesuai tabel dengan indikator penelitian yang telah disediakan kemudian melakukan peninjauan kembali sesuai dengan catatan lapangan yang ada.. 


\section{PEMBAHASAN}

Wujud kesantunan berbahasa adalah keinginan setiap penutur untuk mendapatkan informasi dari mitra tutur tanpa adanya paksaan dan adanya pematuhan prinsip kesantunan berbahasa. Terdapat 18 data dari kesantunan berbahasa. Di bawah ini di uraikan analisis tentang kesantunan berbahasa sebagai berikut.

Data 1

Ag : "Pirang lembar mau lek ngongkon fotokopi bu guru"

Ta : 'Yo sak akehe arek nak kelase dewe iki lah”

Ag : "Oh iyolah. Cek aku ae seng motokopi. Menisan aku atene tuku buku”

Percakapan antara Ag dan Ta mengandung maksim kearifan. Maksim kearifan tersebut muncul ketika Ag mengutarakan maksudnya untuk tugas untuk teman-teman sekelasnya bersamaan dengan ia membeli buku di koperasi sekolah seperti yang terlihat pada tuturan berbahasa jawa 'Oh iyolah. Cek aku ae seng motokopi. Menisan aku atene tuku buku'. Pada tuturan menandakan bahwa Ag merelakan dirinya untuk membantu Ta memfotokopikan tugas tersebut bersamaan dengan ia membeli buku. Pada tuturan membuktikan Ag berusaha membuat kerugian pada Ta sekecil mungkin dan membuat keuntungan Ta sebesar mungkin. Dapat disimpulkan tuturan mengandung maksim kearifan. Data lain yang ditemukan oleh penulis yang mengandung maksim kearifan dapat dilihat pada data 2 sebagai berikut.

\section{Data 2}

$\mathrm{Nb}$ : "Endi buku awakdewe mau, Ndi?"

Fd : "Onok nak mejo mau, enteni diluk tak jupukno sek"

Percakapan antara Nb dengan Fd seperti di atas mengandung maksim kearifan. Maksim kearifan muncul ketika Fd menjawab pertanyaan Nb. Pada saat itu, Nb menanyakan dimana keberadaan buku kelompok mereka yang kemudian langsung dijawab oleh $\mathrm{Nb}$ seperti pada tuturan berbahasa jawa 'onok nak mejo mau, enteni diluk tak jupukno sek‘ Maksud tuturan dari tuturan pada data 2 adalah bahwa Fd mengetahui letak buku kelompok itu. Fd juga merelakan dirinya untuk mengambil buku tersebut. Tuturan pada data 2 menegaskan bahwa Fd berusaha membuat kerugian pada Nb sekecil mungkin dan membuat keuntungan pada Nb pun sebesar 
mungkin. Dapat disimpulkan bahwa tuturan pada data 2 mengandung maksim kearifan.

Selanjutnya, penulis juga menemukan wujud tuturan maksim kearifan antara siswa dengan guru yang terdapat pada data 3 sebagai berikut.

Data 3

Pt : “Ada apa, Buk?”

Ibst : "Ini. Motor Ibu tidak bisa keluar. Motor ini yang menghalangi"

Pt : “Oh, biar saya saja yang mengeluarkannya, Bu”

Percakapan antara Pt dan Ibst mengandung maksim kearifan. Maksim kearifan ini timbul ketika Pt melihat tingkah laku Ibst. Pt merasa iba terhadap Ibst yang kebingungan untuk mengeluarkan motornya yang terhadang dengan motor lainnya. Oleh karena itu, Pt berinisiatif untuk membantu Ibst untuk mengeluarkan motor tersebut dengan tuturan seperti pada tuturan 'Oh, biar saya saja yang mengeluarkannya, Bu'. Maksud dari tuturan 'Oh, biar saya saja yang mengeluarkannya, Bu'. pada data 3 adalah bahwa Pt merelakan dirinya untuk membantu Ibst mengeluarkan motor milik Ibst yang terhalang dengan motor lainnya. Ini menunjukkan bahwa Yg berusaha membuat kerugian pada Ibst berkurang dan keuntungan pada Ibst pun bertambah. Sebaliknya, kerugian Pt bertambah dan keuntungan Pt berkurang.

Data 4

Ard : “Tontok'en talah rabutmu Tur"

Ctr : "Hahaha... iyo, wes dowo. Ayo awakdewe potong rambut pas moleh ngkok, yok?”

Ard : "Oke. Aku yo atene ngrapikno rambut iki saitik. Tapi, aku gak gowo duwek"

Ctr : "Gaweo duwekku sek"

Ard : “Bener?' (benar?)"

Ctr : "Iyo, gawe’en sek. Moleh sekolah iki, yo?”

Ard : "Sido kan lek ngono"

Maksim kedermawaan timbul ketika Ars menyatakan kemauannya ingin merapikan rambut namun ia tidak membawa uang yang kemudian dijawab oleh Gh pada tuturan berbahasa jawa 'gaweo duwekku sek'. Maksud dari tuturan berbahasa jawa gaweo duwekku sek'pada data 5 adalah bahwa Ctr memberikan pinjaman uang kepada Ard agar Ard juga dapat merapikan rambutnya bersama dengan Ctr sehabis 
pulang sekolah. Ini menunjukkan bahwa Ctr berusaha membuat keuntungan pada dirinya berkurang dan membuat kerugiannya membesar karena meminjamkan sebagian uangnya kepada Ard. Selain itu, pada data 5 juga mengandung maksim kesepakatan yang terlihat pada tuturan 'Jadi juga kalau begitu’.

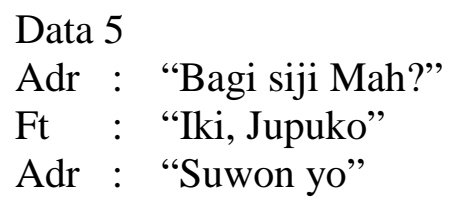

Maksim kedermawaan timbul ketika Adr meminta jajanan milik Ft yang kemudian Ft menjawab seperti pada tuturan 'Ini. Ambilah'. Maksud tuturan 'Ini. Ambilah' pada data 7 adalah bahwa Ft memberikan jajanannya yang diminta oleh Adr. Ft merelakan jajanannya yang seharusnya ia makan diberikan kepada Adr. Ini menunjukkan bahwa Ft menerapkan maksim kedermawaan yaitu Ft berusaha membuat keuntungan pada dirinya mengecil dan kerugian pada dirinya membesar. Ini membuktikan bahwa tuturan 'Ini. Ambilah’ mengandung maksim kedermawanan. Selanjutnya, Peneliti juga menemukan tuturan yang mengandung maksi kedermawanan di dalam percakapan antara siswa dan guru. Tuturan tersebut dapat dilihat pada data 6 sebagai berikut.

Data 6

Ibo : "Ini ada Pak Bima. Beliau mau penelitian di sini. Coba tolong kasihkan Pak Bima kursi.”

Kmb : "Ini, Pak. Duduk di kursi saya saja, Pak"

Percakapan antara Ibo dan Kmb mengandung maksim kedermawaan. Maksim kedermawaan muncul ketika Ibo meminta salah satu siswanya yang mau memberikan kursinya kepada peneliti. Dengan inisiatif sendiri, Kmb memberikan kursinya kepada peneliti sesuai permintaan Ibo seperti pada tuturan 'Ini, Pak. Duduklah di kursi saya saja, pak’. Hal ini menunjukkan bahwa Kmb berusaha memaksimalkan kerugian bagi diri sendiri dan meminimalkan keuntungan diri sendiri. Ini membuktikan tuturan 'Ini, Pak. Duduklah di kursi saya saja, pak’ mengandung maksim kedermawanan.

Data 7

Mk : "Bude...Bude... Sepertinya Dinda hari ini ada yang baru"

Mcl : "Beda sekali dia hari ini" 
Dnd : “Apa yang kalian bicarakan ini?”

Mcl : "Dinda kerudung baru ya?"

Dnd : "Iya. Baru beli kemarin"

Mcl : "Bagus, sekali terlihat cantik"

Dnd : "Makasih"

Percakapan antara $\mathrm{Mk}$, Mcl dan Dnd mengandung maksim pujian. Maksim pujian ini timbul ketika Mk dan Mcl menyadari rambut Dnd mengalami perubahan. Mcl memuji kerudung baru Dnd yang membuat Dnd terlihat cantik. Ini terlihat pada tuturan 'Bagus, sekali terlihat cantk'. Tuturan menandakan bahwa Mcl berusaha memberikan pujian kepada Dnd. Ini membuktikan bahwa tuturan mengandung maksim pujian.

Selain pada data 7 dengan tuturan yang mengandung maksim pujian, peneliti juga menemukan penerapan maksim pujian tersebut pada data 8. Berikut rinciannya.

Data 8

$\mathrm{Nd}$ : "Wah, apik temen yo finalis the next master maen mambengi"

$\mathrm{Ar}$ : "Iyo temen, apik temenan permainane. Aku sueneng seng lanang iku apik”

Percakapan pada data 8 seperti di atas mengandung maksim pujian. Maksim pujian muncul ketika Nd mengomentari penampilan salah satu finalis the next master yang hebat. Ini terlihat pada tuturan berbahasa jawa 'Wah apik temen yo finalis the next master maen mambengi. Tuturan tersebut menandakan bahwa Nd mengakui permainan sulap finalis tersebut hebat. Ar yang mendengar ucapan Nd juga mengakui kehebatan permainan sulap finalis tersebut seperti terlihat pada tuturan bahasa jawa 'Iyo temen, apik temenan permainane. Aku sueneng seng lanang iku apik'

Pada tuturan diatas menunjukkan bahwa Nd dan Ar menerapkan maksim pujian. Selanjutnya, peneliti juga menemukan wujud tuturan penerapan maksim pujian pada data 9 sebagai berikut

Data 9

Ss : "Manfaat dari internet itu kan banyak dan kemudian telah kalian tambahkan tadi. Tetapi, bagaimana pendapat kalian tentang siswa atau siswa yang bertegantungan terhadap internet."

Ad : "Wuiiss, Bagus...Bagus..."

Ss : "Sehingga menyebabkan siswa itu malas untuk menjawab soal-soal dengan pikirannya sendiri?” 
Maksim pujian seperti yang terlihat pada tuturan timbul ketika Ss memberikan pertanyaan kepada kelompok dua yang sedang mempresentasikan tugas karya ilmiahnya. Ad yang mendengarkan pertanyaan tersebut mengakui bahwa pertanyaan yang dilontarkan Ss merupakan pertanyaan yang bagus seperti terlihat pada tuturan Wuiiss, Bagus...Bagus...'. Tuturan menunjukan bahwa Ad berusaha memberikan pujian kepada Ad dan mengurangi kecaman terhadap Ss. ini membuktikan bahwa tuturan Wuiiss, Bagus...Bagus...’ mengandung maksim pujian.

Data 10

Btg : “Garap opo, Dam?”

Ad : “Garap tugas mau?"

Btg : "Rajine kon Dam"

Ad : "Gak. Biasa ae. Aku iku cek gak susah maneh engkok"

Percakapan antara Btg dengan Ad pada data diatas dengan tuturan mengandung maksim kerendahan hati. Maksim kerendahan hati ini muncul ketika Btg memuji Ad seperti terlihat pada tuturan yang dituturkan engggunakan bahasa jawa 'rajine kon Dam’. Maksud tuturan adalah bahwa Btg memuji Ad yang rajin mengerjakan tugas. Tuturan yang diucapkan oleh Btg mendapat respon dari Ad seperti pada tuturan yang dituturkan dengan bahasa jawa 'Gak. Biasa ae. Aku iku cek gak susah maneh engkok’. Pada tuturan menjelaskan bahwa Ad merasa ia tidak rajin. Ia bermaksud mengerjakan tugas yang diberikan Ibu Laila agar nanti ia tidak susah lagi mengerjakannya di lain waktu. Ini terlihat bahwa Ad berusaha meminimalisir pujian yang diberikan oleh Btg pada dirinya. Selain pada data 10, peneliti juga menemukan 1 data percakapan antara siswa dengan guru yang menerapkan maksim kerendahan hati pada data 11 sebagai berikut.

Data 11

Rvd : "Pak... Pak... (sambil menyalami tangan Pd)"

$\mathrm{Pz}$ : “Iya. Ada apa, Do?”

Rvd : "Bagaimana tadi pak penampilan saya tadi pak? Nonton bapak tadi kan?”

$\mathrm{Pz} \quad$ : "Nonton Bapak tadi Hebat..hebat...hebat... Bagus juga suara kamu, Do. Bolehlah masuk dapur rekaman ya?”

Rvd : "Aih Bapak. Bisa sekali memuji. Biasa saja tadi pak. Masih ada yang salah tadi”

$\mathrm{Pz} \quad$ : “Tidak apa-apa. Namanya juga lagi belajar nampil” 
Tuturan di atas mengandung maksim kerendahan hati. Ini terlihat pada tuturan 'Aih Bapak. Bisa sekali memuji. Biasa saja tadi pak. Masih ada yang salah tadi. Tuturan ini timbul dikarenakan Pz memuji penampilan dari Rvd pada pentas seni. Kemudian, Pz menjawab dengan tuturan. Maksud tuturan'Aih Bapak. Bisa sekali memuji. Biasa saja tadi pak. Masih ada yang salah tadi. bahwa Rvd merasa penampilannya masih biasa-biasa saja. Penampilannya pun masih ada yang salah. Rvd berusaha bahwa tidak terlihat berbangga diri dan sombong terhadap pujian dari Pz. Rvd berusaha menerapkan maksim kerendahan hati dengan meminimalisirkan pujian terhadap diri sendiri.

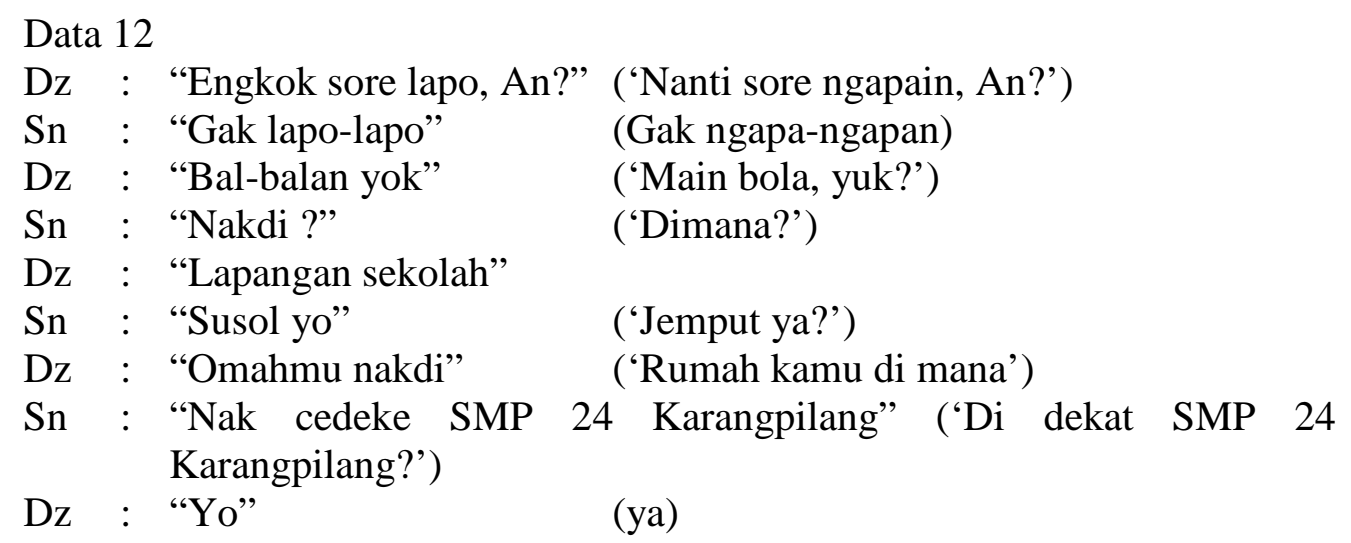

Tuturan di atas mengandung maksim kesepakatan. Maksim kesepakatan tersebut timbul ketika Sn meminta Dz untuk menjemputnya di rumah ketika hendak bermain bola pada sore harinya yang kemudian Dz menjawab dengan tuturan 'Yo'. Maksud dari tuturan bahwa Dz menyepakati bahwa ia nanti akan menjemput Sn.Ini membuktikan bahwa data 12 dengan tuturan 'Yo' menerapkan maksim kesepakatan. Tuturan-tuturan lain yang mengandung maksim kesepakatan dapat kita lihat pada data 13 sebagai berikut.

Data 13

Kmb : "Sin aku oleh nyelang duwekmu?"

Snd : "Gawe opo?"

Kmb : "Gawe tuku Batagor ambek Somay"

Snd : "Tapi sakmarine pelajaran iki yo"

Kmb : "Oke"

Snd : "Mene-mene balekno tapi yo"

Kmb : "Oke" 
Maksim kesepakatan di atas timbul ketika Kmb meminta Snd untuk bersedia meminjamkan ia uang yang akan ia gunakan untuk membeli batagor dan somay yang kemudian dijawab Snd dengan tuturan berbahasa jawa 'tapi sakmarine pelajaran iki yo’ Kmb kemudian menjawab dengan tuturan Oke. Pada tuturan Oke menunjukkan bahwa Kmb sepakat dengan apa yang dikatakan oleh Snd. Kemudian, Snd menyakinkan kepada Kmb bahwa uang tersebut harus dikembalikan diesokkan harinya. Kmb kembali menjawab seperti pada tuturan Oke. Tuturan menandakan bahwa Kmb sepakat bahwa uang Snd akan dikembalikan pada esok harinya. Ini membuktika bahwa tuturan Oke menerapkan maksim kesepakatan.

Selanjutnya, tuturan-tuturan yang mengandung maksim kesepakatan antara siswa dengan guru dapat terlihat pada data 14 dan 15 sebagai berikut.

Data 14

Ibs : "Kan dalam tata krama kita, kan yang tua dihormati. Sama besar, kita hargai. Yang kecil kita sayangi. Iya kan?”

Boy : "Betul sekali itu, Bu. Setuju saya dengan Ibu."

Pada tuturan di atas menunjukkan bahwa data 14 mengandung maksim kesepakatan. Maksim itu timbul ketika Ibs mengajukan sebuah pernyataan bagaimana tata krama bersikap kepada orang yang lebih tua, sebaya dan yang lebih muda di dalam masyarakat. Pernyataan dari Ibs mendapatkan respon dari Boy yang menyetujui apa dikatakan oleh Ibs. Ia sepakat dengan ujaran tersebut seperti terlihat pada tuturan 'Betul sekali itu, Bu. Sepakat saya dengan Ibu.'

Selain itu, penerapan maksim kesepakatan pada tuturan siswa dengan guru dapat dilihat pada data 15 sebagai berikut.

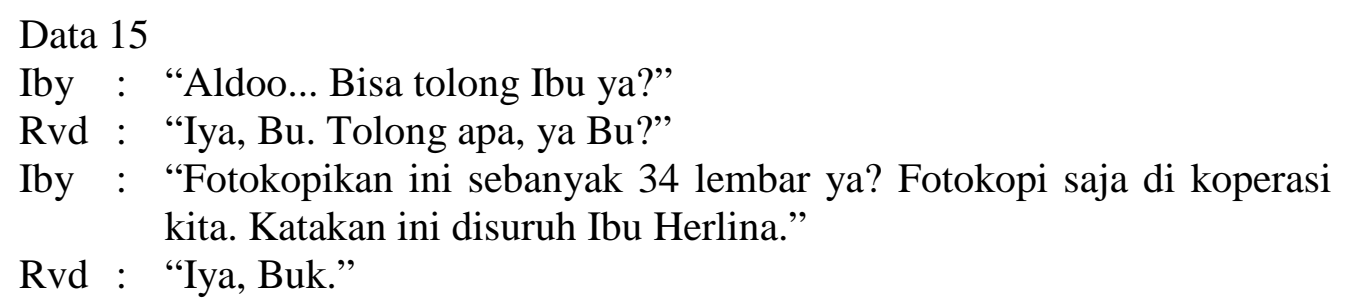

Percakapan antara Iby dan Rvd dari data diatas mengandung maksim kesepakatan. Maksim kesepakatan ini muncul ketika Ibh ingin meminta tolong kepada Rvd. Rvd Merespon permintaan Iby seperti pada tuturan Iya, Buk. Tolong apa, ya Buk? Tuturan 
menandakan bahwa Rvd mengabulkan permintaan dari Iby. Kemudian, Iby meminta kepada Rvd untuk memfotokopikan sesuatu di koperasi sekolah dengan mengatasnamakan namanya. Rvd pun mengabulkan kembali permintaan dari Iby yang terlihat pada tuturan Iya, Buk. Tuturan 'Iyya, Bu. Tolong apa, ya Bu?' dan Iya, Buk. menandakan bahwa Rvd menyepakati apa yang dimintai oleh Iby terhadap dirinya.

\section{Data 16}

$\mathrm{Nb}$ : “Kenapa kamu, Han? Sakit?”

$\mathrm{Hn}$ : "Iya"

$\mathrm{Nb}$ : "Pucat sekali muka, kamu”

$\mathrm{Hn}$ : "Iya"

$\mathrm{Nb}$ : “Apa yang sakit, Han?”

$\mathrm{Hn}$ : "Kepalaku pusing. Badan saya dingin."

$\mathrm{Nb}$ : "Masyaallah. Kita ke UKS saja ya. Kasian kamu kalau dipaksa. Nanti aku yang izinkan ke Ibunya."

Maksim kesimpatian muncul ketika Nb melihat kondisi Hn yang sakit. Ia merasa kasihan dan mengajak Hn untuk ke UKS saja yang terlihat pada tuturan 'Masyaallah. Kita ke UKS saja ya. Kasian kalau dipaksa. Nanti aku yang izinkan ke Ibunya'. Maksud dari tuturan dari $\mathrm{Nb}$ adalah bahwa $\mathrm{Nb}$ kasihan dengan kondisi Hn. Ia mengajak Hn untuk ke UKS agar dapat beristirahat saja di sana. Untuk izin tidak bisa mengikuti pelajaran, Nb rela mengizinkan $\mathrm{Hn}$ ke Ibu guru yang mengajar pada saat itu. Ini menunjukkan bahwa tuturan Nb sebagai bentuk kesimpatian kepada Hn yang sedang sakit.

Selanjutnya, penulis juga menemukan wujud tuturan yang menerapkan maksim kesimpatian antara siswa dengan siswa yang terlihat pada data 17 sebagai berikut.

\section{Data 17}

Ag : "Woi, dekat rumah ku kemarin ada kecelakaan. Motor sama mobil. Parah kecelakaannya”

Rn : "Ya Allah......"

Ag : "Iyo. Motor itu melaju kencang dari arah Balasklumprik. Tiba-tiba mobil yang ada di depannya itu berhenti mendadak. Tidak bisa mengelak yang motor tadi. Akibatnya menabrak kaca belakang mobil. Karena kencangnya termasuk badannya ke dalam mobil. Woi, darah semua. Katanya koma laki-laki itu.”

Rn : "Ya Allah. Kasian ya. Menyilu aku dengarnya." 
Percakapan antara Rn dengan Ag mengandung maksim kesimpatian. Maksim kesimpatian timbul ketika Ag menceritakan peristiwa kecelakaan yang terjadi di dekat rumahnya. Kecelakaan itu menyebabkan pengemudi sepeda motor mengalami koma. Mendengar peristiwa tersebut, Rn merasa simpati terhadap peristiwa tersebut seperti terlihat pada tuturan Ya Allah. Kasian ya. Menyilu aku dengarnya'. Maksud dari tuturan bahwa Rn seolah-olah merasakan apa yang dirasakan oleh pengemudi sepeda motor sehingga ia merasa iba. Ini membuktikan bahwa tuturan Ya Allah. Kasian ya. Menyilu saya dengarnya'. Termasuk maksim kesimpatian. Selain data 16 dan 17, peneliti juga menemukan percakapan antara guru dan siswa yang menerapkan maksim kesimpatian. Percakapan tersebut terdapat pada data 18 sebagai berikut.

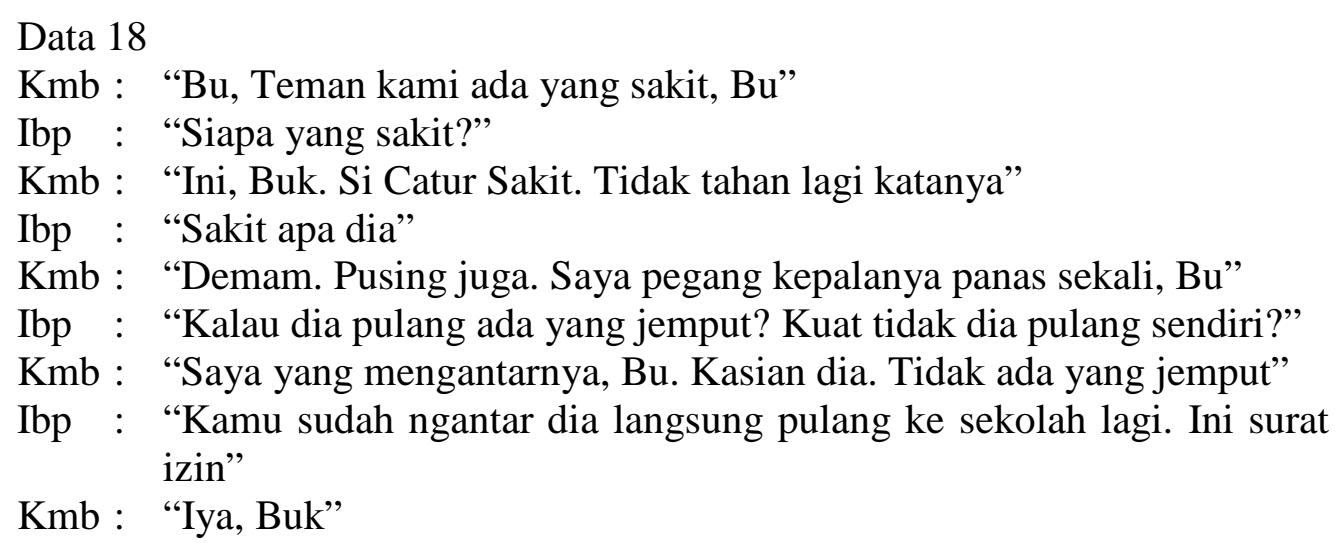

Percakapan antara Kmb dan Ibp di atas mengandung maksim kesimpatian. Maksim kesimpatian timbul ketika Kml ingin meminta izin kepada Ibp untuk mengizinkan temannya yang sakit pulang ke rumah. Kmb merasa kasian dengan temannya sehingga ia mau mengantarkan temannya pulang ke rumah seperti terlihat pada tuturan Saya yang mengantarnya, Bu. Kasian dia. Tidak ada yang jemput' Tuturan menunjukkan kesimpatian Kmb terhadap temannya yang tidak ada menjemputnya untuk pulang ke rumah.

\section{PENUTUP}

Dari fokus penelitian dan pembahasan, dapat disimpulkan bahwa kesantunan berbahasa siswa di SMA Muhammadiyah 4 Surabaya terlihat ketika siswa bertutur sesuai dengan maksim kearifan, maksim kedermawanan, maksim pujian, maksim 
kerendahan hati, maksim kesepakatan dan maksim kesimpatian. Bentuk-bentuk tuturan yang dimaksud adalah bentuk tuturan impositif, komisif, ekspresif dan asertif.

\section{DAFTAR RUJUKAN}

Djadjasudarma, Fatimah. 1993. Metode Linguistik Ancangan Metode Penelitian dan Kajian. Bandung: PT Eresco.

Leech, Geoffrey. 1993. Prinsip-prinsip Pragmatik (terjemahan M.D.D. Oka). Jakarta: UI Press.

Moleong, Lexy J. 2007. Metodologi Penelitian Kualitatif; Edisi Revisi. Bandung: PT Remaja Rosdakarya.

Satori, Djam'an dan Komariah, Aan. 2011. Metode Penelitian Kualitatif. Alfabeta: Bandung. 